\title{
Dissecting brain tumor growth and metastasis in vitro and ex vivo
}

\author{
Michael A. Grotzer ${ }^{1,2}$, Anuja Neve ${ }^{1,2}$, Martin Baumgartner ${ }^{1,2}$ \\ ${ }^{\prime}$ Department of Oncology, University Children's Hospital Zürich, Steinwiesstrasse 75, CH-8032 Zürich, Switzerland. \\ ${ }^{2}$ Children's Research Center, University Children's Hospital Zürich, August-Forel Strasse 1, CH-8008 Zürich, Switzerland.
}

Correspondence to: Dr. Martin Baumgartner, Department of Oncology, University Children's Hospital Zürich, August-Forel Strasse 1, CH-8008

Zürich, Switzerland. E-mail: Martin.Baumgartner@kispi.uzh.ch

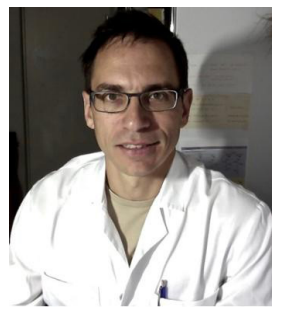

Dr. Martin Baumgartner is a research group leader at the Children's Research Center of the University Children's Hospital Zürich and private docent at the Science Faculty of the University of Zürich. Martin Baumgartner obtained a Ph.D. from the Pasteur Institute and the Université Pierre et Marie Curie in Paris and did postdoctoral work at the University of California San Francisco and the Universities of Zürich and Bern.

\section{A B S T R A C T}

Local infiltration and distal dissemination of tumor cells hamper efficacy of current treatments against central nervous system (CNS) tumors and greatly influence mortality and therapy-induced long-term morbidity in survivors. A number of in vitro and ex vivo assay systems have been established to better understand the infiltration and metastatic processes, to search for molecules that specifically block tumor cell infiltration and metastatic dissemination and to pre-clinically evaluate their efficaciousness. These systems allow analytical testing of tumor cell viability and motile and invasive capabilities in simplified and well-controlled environments. However, the urgent need for novel anti-metastatic therapies has provided an incentive for the further development of not only classical in vitro methods but also of novel, physiologically more relevant assay systems including organotypic brain slice culture. In this review, using publicly available peer-reviewed primary research and review articles, we provide an overview of a selection of in vitro and ex vivo techniques widely used to study growth and dissemination of primary metastatic brain tumors. Furthermore, we discuss how our steadily increasing knowledge of tumor biology and the tumor microenvironment could be integrated to improve current research methods for metastatic brain tumors. We believe that such rationally improved methods will ultimately increase our understanding of the biology of brain tumors and facilitate the development of more efficacious antimetastatic treatments.

Key words: Primary brain tumor; metastasis; in vitro model system; cell migration; organotypic brain slice culture

\section{INTRODUCTION}

Impressive achievements in genomic and epigenomic analyses of tumor tissues and individual tumor cells have revolutionized our understanding of primary brain tumors. Alterations detected on the genome or transcriptome level in large patient cohorts in combination with our increasing understanding of epigenetic gene regulation have

\begin{tabular}{|l|l|}
\hline \multicolumn{3}{|c|}{ Access this article online } \\
\hline Quick Response Code: & $\begin{array}{l}\text { Website: } \\
\text { http://jcmtjournal.com }\end{array}$ \\
\hline
\end{tabular}

disentangled apparently identical brain tumors as related but functionally different tumor entities. ${ }^{[1-5]}$ Within such single tumor entities, alterations detected in their respective metastases suggested potential driver mechanisms of tumor progression. ${ }^{[6]}$ This considerably more complex image we currently have is instrumental to better understand the highly heterogeneous nature of the tumor tissue itself and of the host environment interacting with it and shaping some of

This is an open access article distributed under the terms of the Creative Commons Attribution-NonCommercial-ShareAlike 3.0 License, which allows others to remix, tweak, and build upon the work non-commercially, as long as the author is credited and the new creations are licensed under the identical terms.

For reprints contact: service@oaepublish.com

How to cite this article: Grotzer MA, Neve A, Baumgartner M. Dissecting brain tumor growth and metastasis in vitro and ex vivo. J Cancer Metastasis Treat 2016;2:149-62.

Received: 13-01-2016; Accepted: 09-03-2016. 
its spatial, functional and morphological manifestations. However, in order to translate this still growing knowledge into clinical applications targeting the tumor phenotype, sophisticated model systems are necessary to explore and validate potential interference strategies under physiologically relevant conditions. In addition, functional genomics and cell-based molecular analyses are indispensable in many cases to clarify whether mutated or amplified genes are necessarily contributory to an altered proteome and causative for the cancerous phenotype. Moreover, the current wealth of genomic and transcriptomic data is insufficient on its own to isolate specific signaling networks driving tumor progression from a benign lesion to a disseminated cancer. Hence, to tackle the complexity of the metastatic process it is necessary to dissect it into individual steps that can be addressed with rationally adapted model systems. In this review we focus on in vitro and ex vivo primary brain tumor model systems and discuss how they can be improved and used to develop the molecular understanding necessary for designing novel anti-metastatic therapies. While none of these model systems on its own will suffice to tackle such a complex disease as cancer, they can effectively guide our search for efficacious and less toxic therapies and instruct the design of appropriate in vivo studies.

\section{THE MACHINERY: ALTERED CYTOSKELETON DYNAMICS AND CELL MOTILITY DRIVE CANCER DISSEMINATION}

Dissemination of tumor cells from the primary tumor causes healthy tissue infiltration and metastatic disease, and it hampers the efficacy of current cancer treatments. It is triggered by the transient or permanent induction of motility and invasiveness in the tumor cells. An essential prerequisite for primary brain tumor cell migration and invasion is the remodeling of the actin and tubulin cytoskeletons, ${ }^{[7-9]}$ which not only provide force, traction and rigidity but also scaffold signaling complexes in a spatially controlled manner. ${ }^{[10-12]}$ Hence, blocking motility and invasiveness by targeting pro-migratory cytoskeleton dynamics in tumor cells could prevent local tumor cell invasion, further dissemination from proximal metastases and the evolution towards a more aggressive phenotype. In a seminal review by Giese et al., ${ }^{[13]}$ the dichotomy of migration and proliferation in gliomas was recognized as the consequence of antagonistic cell regulation. Consequently, the authors concluded that an approach to influence the underlying mechanisms could be the basis of novel anti-invasive therapy strategies. A computational modeling study predicts that even a small increase in the motile capability of tumor cells, and the consequent short-range dissemination, increases net tumor growth and resistance to targeted therapy ${ }^{[14]}$ [Figure 1]. Indeed, targeting tumor cell motility and invasiveness as a strategy against metastasis is an emerging theme in cancer research, ${ }^{[15-17]}$ and the pro-migratory phenotype in tumor cells has been addressed in the past by a number of approaches that impair cell autonomous migration, cell-cell communication, cell-cell or cell-matrix interaction ${ }^{[15]}$ and references therein). This research led to the development of a number of clinical trial studies for solid tumors with approaches inhibiting various components of the aforementioned pro-migratory determinants. ${ }^{[15]}$

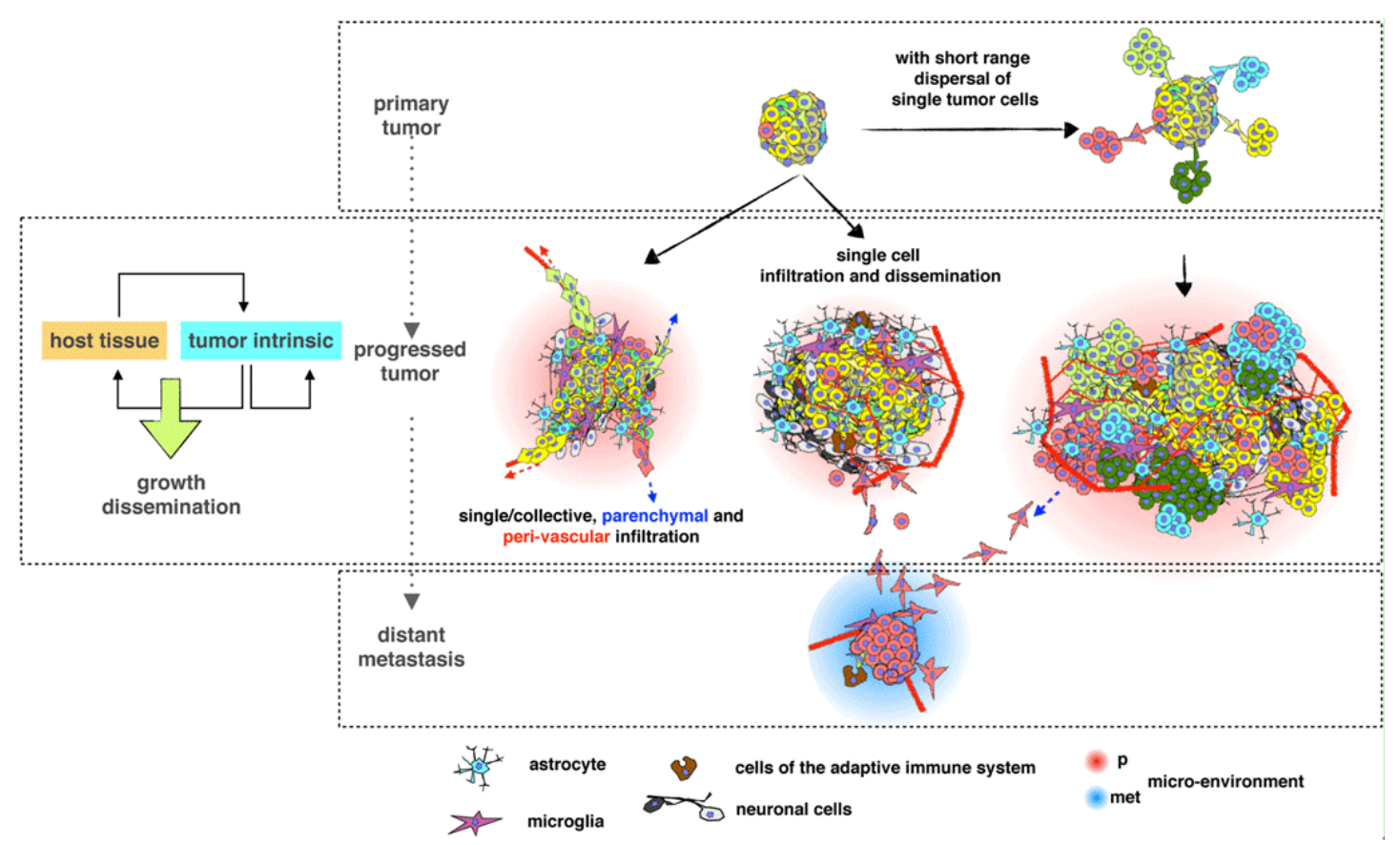

Figure 1: Model of growth, progression and dissemination of primary brain tumors. The progression of primary brain tumors from a small neoplastic lesion to a metastasizing tumor through growth and dissemination of tumor cells is schematically visualized. The mode of tumor cell growth and dissemination varies between different tumors and involves random or guided, single or collective dissemination of tumor cells. The model depicting low range dissemination at early stages and the consequent increased net tumor growth is according Waclaw et al..$^{[14]}$ 
Despite of this, most current treatments including those against primary brain tumors still focus primarily on targeting growth and survival of the tumor cells. This lack of adequate anti-dissemination therapies is due in part to the complexity of the cell migration process itself and the redundancy of the signaling that controls its mechanics.

Additionally, tumor cells exploit mechanisms that normally direct physiological movements. However, the addiction of tumor cells to druggable pathways and our increasing understanding of cell mechanics and its control offer room for therapeutic interventions targeting tumor cell dissemination specifically.

\section{The soil: the microenvironment in the brain}

To address the impact of the tumor microenvironment on tumor growth and progression in vitro, we need (a) to better understand the intricate interaction between a growing neoplasm and its cellular, biophysical and chemical environment and (b) to continuously implement this increasing knowledge for advancing our model systems to mimic the micro environmental parameters better. The following paragraph will briefly discuss some relevant aspects of the still poorly understood interaction between the cells of primary brain tumors and their cellular host environment.

\section{Biophysical properties of the brain microenvironment}

Mammalian cells are sensitive to biophysical and chemical signals emanating from the surrounding matrix environment, the extracellular matrix (ECM), which can influence their behavior. ${ }^{[18-20]}$ Depending on the tissue, composition and stiffness of the ECM differs markedly. ${ }^{[21]}$ The stiffness or rigidity of a material such as a meshwork of collagen I fibers, describes its resistance to deformation. It depends on the elastic modulus (or compliance) of its constituting material e.g. fibrillar polymers of the protein collagen, which describes the ability to resist a distorting influence and to return to its original size and shape when the influence is removed. Thus, the stiffness of the ECM depends on its components and their elastic modulus. As the parenchyma of the brain is mostly devoid of fibers with a high elastic modulus such as collagen or fibronectin fibrils, its stiffness is very low compared to the ECMs in other tissues of the human body. ${ }^{[22]}$ Conversely, the leptomeniges in the subarachnoid space, to where metastatic medulloblastoma tumors preferentially spread, ${ }^{[22]}$ are connected by a network of collagen-rich trabeculae, ${ }^{[23,24]}$ which likely is much stiffer than the parenchyma.

The basic constituents of the brain ECM are glycosaminoglycans with their most prominent member hyaluronan (Hyaluronic acid, HA), link proteins, lecticans and tenascins. ${ }^{[25]} \mathrm{HA}$ acts as a backbone for the assembly of a relatively loose and flexible meshwork. The distribution and composition of these ECM components in the developing rodent brain is changing during embryonal and postnatal phases and reaches a mature stage at postnatal day 20. ${ }^{[25]}$ However, disease-associated remodeling of the CNS ECM has been observed after injury, ${ }^{[25-28]}$ suggesting that growing primary neoplasms in the brain may also alter the surrounding ECM. Relatively little change in the expression levels of a small set of proteins in normal brain tissue and in brain tissue surrounding invasive glioblastoma was observed in a recent study, ${ }^{[29]}$ except for Tenascin-R and CD168, which were both up-regulated. Matrix stiffness regulates proliferation and motility of Glioblastoma multiforme (GBM) cells ${ }^{[30]}$ and the increase of ECM stiffness through fiber crosslinking by the product of the LOX gene causes their enhanced integrin-dependent invasion. ${ }^{[31]}$ The specific impact of matrix stiffness on cell migration was investigated in glioma and found to decrease motility in agarose-stiffened collagen gels ${ }^{[19]}$ and to increase motility in matrigel. ${ }^{[32]}$ This somewhat conflicting result may be explained by the receptors sensing the matrix environment and their underlying signaling, which markedly influence the migratory outcome. Hence, the impact of matrix stiffness on the migratory behavior should always be investigated in the context of the cognate receptors. Whether matrix stiffness could exert a selective pressure on brain tumor cells contributing to the altered genetic landscapes is still poorly understood. One potential sensor and transducer of matrix stiffness in brain tumors is the HA receptor CD44, which was identified in GBM to facilitate invasiveness in stiff matrices. ${ }^{[33]}$

\section{Chemical properties of the brain microenvironment}

Analogous to solid tumors outside the CNS, where parallels between the inflammatory response in wounds and the host tissue response to growing neoplasms has been noted, ${ }^{[34]}$ remarkable similarities in brain tissue response after injury and in the vicinity of brain tumors exist. ${ }^{[35]}$ Tissue response is driven initially by a local repertoire of innate and adaptive immune cells that is subsequently supported by infiltrating cells of the adaptive immune system. In the brain, an immune privileged site of the human body, tissue response is driven by microglia/macrophages and astrocytes. Microglia are involved in first-line innate immunity in response to brain injury, when they convert to an active proliferating, migrating and phagocytic phenotype. ${ }^{[36]}$ Microglia and macrophages accumulate in and around glioma to which they are suspected to be attracted by glioma-secreted chemo attractants such as monocyte chemotactic protein-3 (MCP3 ), colony-stimulating factor 1 (CSF-1), granulocytecolony stimulatory factor (G-CSF), and hepatocyte growth factor/scatter factor. ${ }^{[37]}$ Besides direct stimulatory functions through secretion of growth factors or proteolytic enzymes, glioma infiltrating macrophages were also found to contribute to tumor vascularization and net tumor growth. ${ }^{[38]}$ Surprisingly, however, malignancy or primary cranial origin did not seem to determine immune cell infiltration as no significant difference in immune cell distribution was observed between different primary or secondary brain malignancies (Glioma, PNET/Medulloblastoma, 
adenocarcinoma, melanoma meningioma). ${ }^{[39]}$ A more recent study correlating inflammatory gene expression with the molecular subgroup of medulloblastoma, revealed significantly increased immune cell infiltration of tumor associated macrophages and other immune cells in the $\mathrm{SHH}$ subgroup, ${ }^{[40]}$ suggesting a potential therapeutic relevance of immune cell targeting specifically for this subgroup.

Microglia are outnumbered by astrocytes, which account for nearly half of all cells resident in the brain. Astrocytes respond to brain injury and tumor growth in a process named reactive gliosis. On the one hand, reactive gliosis and the associated secretion of growth factors and cytokines help repairing injury in the $\mathrm{CNS}^{\left[{ }^{[1]}\right.}$ On the other hand, the astrocytic response in the tumor microenvironment also contributes to disease progression. Of note in this context is the capability of U87MG glioblastoma cells to induce astrocyte activation through the secretion of Receptor Activator of NF-kB ligand (RANKL), which in turn facilitates glioblastoma invasiveness in vivo by releasing FGF4, FGF6, TGF- $\beta$ and Hepatocyte growth factor. $^{[42]}$ Consistently, co-cultured astrocytes display increased expression levels of a number of growth factors and cytokines and enhance invasiveness of glioblastoma stem-like cells. ${ }^{[43]}$ Another decisive input could stem from astrocytes activated by the neoplastic lesion and the consequent up-regulation of matricellular proteins such as secreted protein acidic and rich in cys-teins (SPARC) in astrocytoma ${ }^{[44]}$ and medulloblastoma ${ }^{[45]}$ or connective tissue growth factor in glioma, ${ }^{[46]}$ which jointly with additional matricellular proteins remodel neuronal tissue during development or after brain injury. ${ }^{[28]}$ Significantly, the concept of reciprocal stimulation of tumor cells and astrocytes was recently also identified in metastatic melanoma, which elicits an inflammatory cytokine response in astrocytes that facilitates brain metastasis. ${ }^{[47]}$

Combined, these studies emphasize the importance of incorporating environmental parameters into experimental protocols to explore their contribution to the proteomic landscape and the functional outcomes of primary brain tumors.

\section{CURRENT IN VITRO MODEL SYSTEMS TO ADDRESS FUNCTIONS OF METASTATIC PRIMARY BRAIN TUMORS}

Preclinical evaluation of novel anti-metastatic therapy strategies in animal models will remain an essential step towards the development of novel therapeutics. However, cell culture models are instrumental for deciphering essential morphological and functional aspects of the biology that drives neoplastic lesions into disseminated diseases. They also provide essential insights for designing appropriate animal models and help elucidating the causes that may underlie controversial outcomes of in vivo studies. Although a general trend towards 3D model systems can be noted, a majority of experiments in tumor-related research are still conducted in $2 \mathrm{D}$ settings. For a general, in depth description and comparison of $2 \mathrm{D}$ versus $3 \mathrm{D}$ culture systems, the reader is referred to Zimmermann et al. ${ }^{[48]}$ who emphasized the need of higher throughput approaches to understand cell dissemination capabilities on one hand and the role of the microenvironment on the other hand.

The "ideal" in vitro cell culture model should mimic one or several of the following characteristics of the in vivo tumor: proliferative capabilities and morphology of the tumor cells, cellular and phenotypic heterogeneity, a dynamic tumor microenvironment and the drug response profile. A series of excellent reviews have recently described in depth the use of 3D tissue culture model systems in pathophysiology ${ }^{[49]}$ and high-throughput drug candidate toxicity analysis, ${ }^{[50]}$ to identify tumor-specific signaling pathways and biomarkers, ${ }^{[51]}$ and to determine growth determinants for drug target discovery. ${ }^{[52]}$ These reviews delineate what parameters contribute to a disease representing, efficient
3D

spheroid not embedded
3D

spheroid matrix embedded
3D

organotypic environment
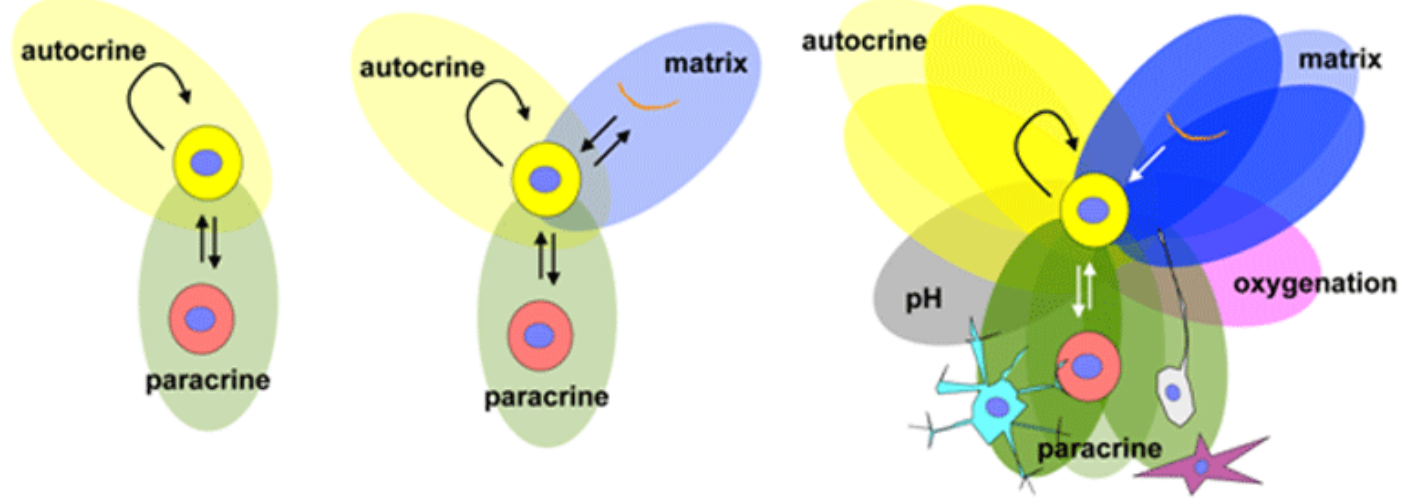

Figure 2: Tumor cell growth, survival and dissemination are governed by extrinsic and intrinsic parameters. Tumor cells are under the spheres of influence of intrinsic and extrinsic parameters. Colored ovals represent various degrees and manifestation patterns of such parameters, which dramatically increase in number and complexity in the organotypic environment 
Table 1: Studies using 3D primary brain tumor model systems

\begin{tabular}{|c|c|c|c|c|c|c|}
\hline Cells & Tumor type & Condition & Experiment & $\begin{array}{l}\text { Matrix or } \\
\text { scaffold }\end{array}$ & Effect & Ref. \\
\hline U87MG & $\begin{array}{l}\text { Glioblastoma } \\
\text { multiforme } \\
(\mathrm{GBM})\end{array}$ & $\begin{array}{l}2 \mathrm{D}, 3 \mathrm{D} \\
\text { neurospheres }\end{array}$ & $\begin{array}{l}\text { Analysis of } \\
\text { cell growth in } \\
\text { neurospheres, } \\
\text { wound healing } \\
\text { after DDX6 or } \\
\text { PHLDB1 knock- } \\
\text { down }\end{array}$ & None & $\begin{array}{l}50 \% \text { reduction in } \\
\text { neurosphere formation } \\
\text { and migration }\end{array}$ & {$[83]$} \\
\hline $\begin{array}{l}\mathrm{U}-251 \mathrm{MG}, \\
\mathrm{U}-343 \mathrm{MG}, \\
\mathrm{LN}-229\end{array}$ & Glioma & $\begin{array}{l}2 \mathrm{D}, 3 \mathrm{D} \text { spheroid } \\
\text { culture }\end{array}$ & $\begin{array}{l}\text { Analysis of stable } \\
\text { over-expression } \\
\text { of wt and } \\
\text { mutant proteins } \\
\text { under different } \\
\text { oxygenation. }\end{array}$ & None & $\begin{array}{l}\text { Mutant IDH1 causes } \\
\text { reduced cell migration } \\
\text { and differences in } \\
\text { growth properties in } \\
\text { 3D spheroid cultures. }\end{array}$ & {$[84]$} \\
\hline U87 & GBM & $\begin{array}{l}2 \mathrm{D}, 3 \mathrm{D} \text { single } \\
\text { cell embedding }\end{array}$ & $\begin{array}{l}\text { Spheroid in soft } \\
\text { agar, 2D culture, } \\
\text { analysis of Glioma } \\
\text { co-culture with } \\
\text { MSCs expressing } \\
\text { suicide gene. }\end{array}$ & Soft agar & $\begin{array}{l}\text { Stem cell-mediated } \\
\text { anti-tumor effect. } \\
\text { Increased IC50 under } \\
\text { 3D culture conditions. }\end{array}$ & {$[85]$} \\
\hline $\begin{array}{l}\text { KNS42, U87, } \\
\text { Res 196, } \\
\text { T7/11, GB-1 }\end{array}$ & $\begin{array}{l}\text { Pediatric and } \\
\text { adult GBM and } \\
\text { ependymoma, } \\
\text { pediatric mixed } \\
\text { glial tumor }\end{array}$ & $\begin{array}{l}3 \mathrm{D} \text {, long- } \\
\text { term culture of } \\
\text { large cellular } \\
\text { aggregates }\end{array}$ & $\begin{array}{l}\text { Rotary cell culture } \\
\text { to generate large } \\
\text { cell aggregates, } \\
\text { growth on top of } \\
\text { matrigel. }\end{array}$ & None & $\begin{array}{l}\text { Angiogenic change } \\
\text { and endothelial marker } \\
\text { expression in GBM } \\
\text { aggregates }\end{array}$ & {$[86]$} \\
\hline $\begin{array}{l}\text { SHSY } 5 Y, \\
\text { T98G, } \\
\text { U138MG }\end{array}$ & $\begin{array}{l}\text { GBM and } \\
\text { neuroblastoma }\end{array}$ & $\begin{array}{l}3 \mathrm{D}, \text { spheroid } \\
\text { culture }\end{array}$ & $\begin{array}{l}\text { Exposure to } \\
\text { Doxorubicin, } \\
\text { Etoposide and } \\
\text { Vincristine, } \\
\text { analysis by } \\
\text { electrochemical } \\
\text { impedance } \\
\text { spectroscopy. }\end{array}$ & None & $\begin{array}{l}\text { Cytotoxic effect } \\
\text { measured in } 2 \mathrm{D} \\
\text { cannot be extrapolated } \\
\text { to 3D. 3D cultures } \\
\text { can also display } \\
\text { higher sensitivity to } \\
\text { chemotherapeutics. }\end{array}$ & {$[58]$} \\
\hline U67-MG & GBM & $2 \mathrm{D}$ & $\begin{array}{l}2 \mathrm{D} \text { wound healing, } \\
\text { tubulogenesis } \\
\text { assay on matrigel } \\
\text { after exposure } \\
\text { to rapamycin or } \\
\text { hypoxia. }\end{array}$ & None & $\begin{array}{l}\text { Tube structure } \\
\text { formation }\end{array}$ & {$[87]$} \\
\hline $\begin{array}{l}\text { Rat C6, } \\
\text { NSCs adult } \\
\text { hippocampal }\end{array}$ & Glioma & $\begin{array}{l}3 \mathrm{D}, \text { spheroid } \\
\text { culture }\end{array}$ & $\begin{array}{l}\text { Comparison of } \\
\text { different 3D tissue } \\
\text { clearing protocols. }\end{array}$ & None & $\begin{array}{l}\text { Validation of tissue } \\
\text { clearing protocols } \\
\text { of high resolution } \\
\text { imaging of spheroid } \\
\text { culture. }\end{array}$ & {$[88]$} \\
\hline U251 & Glioma & $\begin{array}{l}2 \mathrm{D} \text { and } 3 \mathrm{D} \\
\text { rotary cell } \\
\text { culture system }\end{array}$ & $\begin{array}{l}\text { Proteomic } \\
\text { comparison of 2D } \\
\text { and 3D cell culture. }\end{array}$ & None & $\begin{array}{l}\text { Increased HLA-E } \\
\text { expression in 3D } \\
\text { culture and increased } \\
\text { resistance to NK- } \\
\text { mediated cytotoxicity. }\end{array}$ & [89] \\
\hline $\begin{array}{l}\text { DBTRG, T98, } \\
\text { U87, A172, } \\
\text { 8MGBA, } \\
\text { 42MGBA, } \\
\text { DKMG, } \\
\text { GAMG, } \\
\text { GMS10, GSCs }\end{array}$ & GBM & $\begin{array}{l}2 \mathrm{D}, 3 \mathrm{D}, \text { single } \\
\text { cell embedding }\end{array}$ & $\begin{array}{l}\text { Cytotoxicity assays } \\
\text { using collagen } \\
\text { I and collagen } \\
\text { I-HA matrices in } \\
\text { combination with } \\
\text { receptor tyrosine } \\
\text { kinase inhibitors. }\end{array}$ & $\begin{array}{l}\text { Bovine } \\
\text { skin } \\
\text { collagen I, } \\
\text { Collagen } \\
\text { I-HA } \\
\text { mixtures }\end{array}$ & $\begin{array}{l}\text { Collagen-based } \\
\text { 3D matrix reduces } \\
\text { sensitivity of GSCs } \\
\text { to receptor tyrosine } \\
\text { kinase inhibitors. }\end{array}$ & {$[60]$} \\
\hline
\end{tabular}




\begin{tabular}{|c|c|c|c|c|c|c|}
\hline Cells & Tumor type & Condition & Experiment & $\begin{array}{l}\text { Matrix or } \\
\text { scaffold }\end{array}$ & Effect & Ref. \\
\hline $\begin{array}{l}\text { U87-MG, } \\
\text { primary MB } \\
\text { samples }\end{array}$ & GBM & $2 \mathrm{D}, 3 \mathrm{D}$ culture & $\begin{array}{l}\text { Comparison of 2D and } \\
\text { 3D cultures for growth } \\
\text { and viability after } \\
\text { irradiation or treatment } \\
\text { with TMZ, cisplatin or } \\
\text { carmustin. }\end{array}$ & $\begin{array}{l}\text { ExtracelTM } \\
\text { (Polyethylene- } \\
\text { based hydrogel } \\
\text { with HA and } \\
\text { gelatin). }\end{array}$ & $\begin{array}{l}\text { 3D cell culture is } \\
\text { better morphological } \\
\text { correlate to in vivo } \\
\text { tumor, 3D grown } \\
\text { GBM moderately less } \\
\text { sensitive to irradiation. }\end{array}$ & [90] \\
\hline U118-MG & GBM & $\begin{array}{l}3 \mathrm{D} \text { culture, cells } \\
\text { grown on rigid } \\
\text { matrix }\end{array}$ & $\begin{array}{l}\text { Evaluation of } \\
\text { growth and stem cell } \\
\text { properties }\end{array}$ & $\begin{array}{l}\text { Porous chitosan- } \\
\text { HA }\end{array}$ & $\begin{array}{l}\text { Porous chitosan-HA } \\
\text { increases growth and } \\
\text { causes up-regulation of } \\
\text { stem-cell markers }\end{array}$ & {$[63]$} \\
\hline $\begin{array}{l}\text { Patient- } \\
\text { derived tumor } \\
\text { material }\end{array}$ & GBM & 3D, single cells & $\begin{array}{l}\text { Embedding } \\
\text { in hydrogels, } \\
\text { morphology and cell } \\
\text { migration analysis, } \\
\text { single cell tracking for } \\
\text { motility. }\end{array}$ & $\begin{array}{l}\text { Hydrogels made } \\
\text { of collagen I, III, } \\
\text { or collagen-HA } \\
\text { mixtures }\end{array}$ & $\begin{array}{l}\text { HA causes rounded } \\
\text { morphology and } \\
\text { reduces motility of } \\
\text { matrix-embedded cells. }\end{array}$ & {$[62]$} \\
\hline $\begin{array}{l}\text { U87-MG, } \\
\text { U87+EGFR }\end{array}$ & Glioma & $3 \mathrm{D}$, single cells & $\begin{array}{l}\text { Analysis of growth, } \\
\text { metabolic activity } \\
\text { and HIF-1 VEGF, } \\
\text { MMP-2, MMP- } \\
9 \text { and Fibronectin } \\
\text { production. }\end{array}$ & $\begin{array}{l}\text { GelMA or } \\
\text { PEG4A hydrogels } \\
\text { supplemented } \\
\text { with } \\
\text { methacrylated } \\
\text { HA (HAMA) } \\
\text { at increasing } \\
\text { concentrations }\end{array}$ & $\begin{array}{l}\text { Increasing HAMA } \\
\text { concentrations cause } \\
\text { up-regulation of } \\
\text { fibronectin, VEGF and } \\
\text { HIF-1. }\end{array}$ & [64] \\
\hline A-172 & Glioma & $\begin{array}{l}3 \mathrm{D} \text {, single cells, } \\
\text { microfluidic } \\
\text { chip }\end{array}$ & $\begin{array}{l}\text { Analysis of single cell } \\
\text { viability, F-actin size } \\
\text { and cellular orientation } \\
\text { in embedded cells } \\
\text { under flow and VEGF } \\
\text { in microfluidic chip. }\end{array}$ & $\begin{array}{l}\text { Acrylated HA } \\
\text { cross-linked with } \\
\text { MMP-sensitive or } \\
\text { RGD peptides }\end{array}$ & $\begin{array}{l}\text { F-actin reorganization } \\
\text { and re-orientation of } \\
\text { cells in response to } \\
\text { flow and VEGF. }\end{array}$ & [91] \\
\hline OSU-2 & GBM & $3 \mathrm{D}$, single cells & $\begin{array}{l}\text { Evaluation of matrix } \\
\text { stiffness impact on } \\
\text { tumor cell morphology } \\
\text { and migratory/invasive } \\
\text { capabilities. }\end{array}$ & $\begin{array}{l}\text { Matrigel with } \\
\text { varying stiffness }\end{array}$ & $\begin{array}{l}\text { Increased matrix } \\
\text { stiffness causes } \\
\text { increased invasive } \\
\text { motility. }\end{array}$ & {$[32]$} \\
\hline $\begin{array}{l}\text { M059K, } \\
\text { HepG2, } \\
\text { CYP3A }\end{array}$ & $\begin{array}{l}\text { GBM, } \\
\text { Hepatoblastoma }\end{array}$ & $\begin{array}{l}3 \mathrm{D} \text {, micro- } \\
\text { scale perfusion } \\
\text { system }\end{array}$ & $\begin{array}{l}\text { Evaluation of liver } \\
\text { cell metabolism on } \\
\text { cytotoxic effect of IFO } \\
\text { and TMZ. }\end{array}$ & $\begin{array}{l}\text { Polylactic acid } \\
\text { scaffold }\end{array}$ & $\begin{array}{l}\text { TMZ showed much } \\
\text { lower cytotoxicity } \\
\text { against GBM cells in } \\
\text { 3D than in 2D. IFO } \\
\text { effect dependent on } \\
\text { metabolic activity of } \\
\text { cytochrome P450 in } \\
\text { hepatocytes. }\end{array}$ & {$[68]$} \\
\hline $\begin{array}{l}\mathrm{U} 251 \mathrm{MG} \\
\mathrm{LN} 229 \text { and } \\
\mathrm{U} 87 \mathrm{MG}\end{array}$ & GBM & $\begin{array}{l}\text { 3D, organotypic } \\
\text { slice culture }\end{array}$ & $\begin{array}{l}\text { Evaluation of Rho- } \\
\text { family GTPase } \\
\text { activation during } \\
\text { GBM invasion in } \\
\text { brain slice and 3D } \\
\text { matrigel culture. Use } \\
\text { of Rho-family GTPase } \\
\text { fluorescent protein } \\
\text { sensors. }\end{array}$ & $\begin{array}{l}\text { Matrigel, slice } \\
\text { culture }\end{array}$ & $\begin{array}{l}\text { Perivascular and } \\
\text { intraparenchymal } \\
\text { invasion is associated } \\
\text { with increased Rac and } \\
\text { Cdc42 and reduce Rho } \\
\text { GTPase activity. }\end{array}$ & {$[53]$} \\
\hline $\begin{array}{l}\text { U87, U251HF, } \\
\text { SNB19, } \\
\text { LNZ308, } \\
\text { LN229 }\end{array}$ & Glioma & $2 \mathrm{D}, 3 \mathrm{D}$ & $\begin{array}{l}\text { Comparison of protein } \\
\text { expression in cells } \\
\text { grown under 2D or } \\
\text { 3D conditions and in } \\
\text { different oxygenation. }\end{array}$ & AlgiMatrix & $\begin{array}{l}\text { Differential expression } \\
\text { of invasion, survival } \\
\text { and hypoxia driver } \\
\text { proteins between 2D } \\
\text { and 3D. Effect of 3D } \\
\text { growth dominates } \\
\text { oxygenation. }\end{array}$ & [92] \\
\hline
\end{tabular}




\begin{tabular}{|c|c|c|c|c|c|c|}
\hline Cells & Tumor type & Condition & Experiment & $\begin{array}{l}\text { Matrix or } \\
\text { scaffold }\end{array}$ & Effect & Ref. \\
\hline $\begin{array}{l}\text { LN18, GL15, } \\
\text { U87, A172 }\end{array}$ & GBM & $2 \mathrm{D}, 3 \mathrm{D}$ & $\begin{array}{l}\text { Seeding of GBM cells on } \\
\text { brain Hi-spots and exposure } \\
\text { to anti-proliferative drugs } \\
\text { Ara-C, Taxol and TMZ }\end{array}$ & Brain Hi-Spots & $\begin{array}{l}\text { Increased anti- } \\
\text { proliferative effect of } \\
\text { TMZ on GBM cells } \\
\text { maintained on Hi-spots. }\end{array}$ & [65] \\
\hline $\begin{array}{l}\text { C6 rat, U-87 } \\
\text { MG, U-118 MG }\end{array}$ & Glioma & $\begin{array}{l}2 \mathrm{D}, 3 \mathrm{D}, \\
\text { Matrigel and } \\
\text { chitosan- } \\
\text { alginate } \\
\text { scaffolds }\end{array}$ & $\begin{array}{l}\text { Comparison of growth } \\
\text { and morphology and } \\
\text { secretion of VEGF, MMP2, } \\
\text { fibronectin and Laminin } \\
\text { between cells grown in 2D, } \\
\text { in matrigel or on chitosan- } \\
\text { alginate scaffolds. }\end{array}$ & $\begin{array}{l}\text { Matrigel, } \\
\text { Chitosan- } \\
\text { alginate } \\
\text { scaffolds }\end{array}$ & $\begin{array}{l}\text { Growth on chitosan- } \\
\text { alginate scaffolds } \\
\text { reduces growth but } \\
\text { increases secretion } \\
\text { of VEGF, MMP2, } \\
\text { fibronectin and } \\
\text { Laminin. }\end{array}$ & [93] \\
\hline $\begin{array}{l}\text { LN18, F98, } \\
\text { F98EGFR- vIII, } \\
\text { C6 rat, U-87 } \\
\text { MG, }\end{array}$ & Glioma & $\begin{array}{l}2 \mathrm{D}, 3 \mathrm{D} \\
\text { spheroid } \\
\text { culture, } \\
\text { transwell } \\
\text { migration }\end{array}$ & $\begin{array}{l}\text { Evaluation of SHA impact } \\
\text { on cell growth, collagen } \\
\text { I invasion and mRNA } \\
\text { expression of genes relevant } \\
\text { for cell-cell and cell-matrix } \\
\text { interaction. }\end{array}$ & Collagen I & $\begin{array}{l}\text { SAHA treatment causes } \\
\text { reduction of invasion } \\
\text { and the reorganization } \\
\text { of the matrix } \\
\text { surrounding the tumor } \\
\text { spheroids. }\end{array}$ & [94] \\
\hline U178, U251 & Glioma & 3D transwell & $\begin{array}{l}\text { Analysis of transwell } \\
\text { invasion and migration after } \\
\text { compound inhibition of } \\
\text { PKC2. }\end{array}$ & $\begin{array}{l}\text { Collagen I } \\
\text { supplemented } \\
\text { with Tenascin C }\end{array}$ & $\begin{array}{l}\text { Tenascin-C deposition } \\
\text { triggers glioma invasion } \\
\text { in a PKCD-dependent } \\
\text { manner. }\end{array}$ & [95] \\
\hline U373 & Glioma & 3D spheroid & $\begin{array}{l}\text { Analysis of growth } \\
\text { and dissemination in } \\
\text { increasingly stiff collagen I } \\
\text { gels. }\end{array}$ & $\begin{array}{l}\text { Collagen } \\
\text { I-agarose }\end{array}$ & $\begin{array}{l}\text { Matrix stiffness } \\
\text { impacts on glioma } \\
\text { cell invasiveness. } \\
\text { High stiffness blocks } \\
\text { invasiveness. }\end{array}$ & [19] \\
\hline U251, U178 & Glioma & $\begin{array}{l}3 \mathrm{D}, \text { single } \\
\text { cells }\end{array}$ & $\begin{array}{l}\text { Quantification of transwell } \\
\text { migration of cells stimulated } \\
\text { with TNF- } \alpha \text {, IL-1 or a } \\
\text { combination of both. }\end{array}$ & Collagen I & $\begin{array}{l}\text { Interleukin-1 beta (IL- } \\
\text { lb) and tumor necrosis } \\
\text { factor-alpha (TNF- } \alpha \text { ) } \\
\text { increase glioma cell } \\
\text { invasiveness in 3D } \\
\text { with parallel increased } \\
\text { MMP-2 and MMP-9. }\end{array}$ & [96] \\
\hline $\begin{array}{l}\text { Primary mouse } \\
\text { G3 MB }\end{array}$ & Medulloblastoma & $\begin{array}{l}3 \mathrm{D} \\
\text { neurospheres }\end{array}$ & $\begin{array}{l}\text { Neurosphere compound } \\
\text { toxicity assays using FDA- } \\
\text { approved drugs and ATP- } \\
\text { sensor dye. }\end{array}$ & None & $\begin{array}{l}\text { FDA-approved } \\
\text { Pemetrexed and } \\
\text { Gemcitabine } \\
\text { significantly block } \\
\text { proliferation of G3 MB. }\end{array}$ & {$[55]$} \\
\hline DAOY, UW228 & Medulloblastoma & $\begin{array}{l}\text { 2D, 3D } \\
\text { transwell, 3D } \\
\text { micro beads }\end{array}$ & $\begin{array}{l}\text { Quantification of } \\
\text { collagen invasion after } \\
\text { HGF stimulation, small } \\
\text { compound kinase inhibitor } \\
\text { or siRNA treatment in cells } \\
\text { seeded on Micro-beads and } \\
\text { embedded in collagen I } \\
\text { matrix. }\end{array}$ & Collagen I & $\begin{array}{l}\text { HGF-induced c-Met } \\
\text { activation promotes MB } \\
\text { cell invasion through } \\
\text { the kinase MAP4K4. }\end{array}$ & [9] \\
\hline $\begin{array}{l}\text { DAOY, } \\
\text { UW228, Med } \\
\text { PDX1712, } \\
\text { MedPDX411, } \\
\text { primary MB }\end{array}$ & Medulloblastoma & $\begin{array}{l}\text { 2D, 3D micro } \\
\text { beads and } \\
\text { spheroids }\end{array}$ & $\begin{array}{l}\text { Quantification of collagen } \\
\text { invasion and cell migration } \\
\text { after growth factor } \\
\text { stimulation using invasion } \\
\text { counter platform for } \\
\text { automated quantification } \\
\text { of motile cell behavior in } \\
\text { different environments. }\end{array}$ & Collagen I & $\begin{array}{l}\text { HGF, EGF and bFGF } \\
\text { are strong promoters of } \\
\text { MB cell migration and } \\
\text { invasion }\end{array}$ & {$[56]$} \\
\hline
\end{tabular}




\begin{tabular}{|c|c|c|c|c|c|c|}
\hline Cells & Tumor type & Condition & Experiment & $\begin{array}{l}\text { Matrix or } \\
\text { scaffold }\end{array}$ & Effect & Ref. \\
\hline DAOY, UW228 & Medulloblastoma & $\begin{array}{l}3 \mathrm{D} \text {, transwell } \\
\text { migration }\end{array}$ & $\begin{array}{l}\text { Quantification of } \\
\text { VEGE-A induced, } \\
\text { PERK-dependent } \\
\text { transwell migration. }\end{array}$ & Matrigel & $\begin{array}{l}\text { Tumor cell-derived } \\
\text { VEGF-A promotes } \\
\text { medulloblastoma cell } \\
\text { migration and invasion } \\
\text { through VEGFR2 and } \\
\text { enhanced by PERK. }\end{array}$ & {$[97]$} \\
\hline DAOY, UW228 & Medulloblastoma & $\begin{array}{l}3 \mathrm{D} \text {, transwell } \\
\text { migration }\end{array}$ & $\begin{array}{l}\text { Quantification of } \\
\text { EphB1 effect on SHH } \\
\text { medulloblastoma } \\
\text { transwell migration } \\
\text { using electrical } \\
\text { impedance } \\
\text { measurements. }\end{array}$ & None & $\begin{array}{l}\text { Knockdown of Eph-B1 } \\
\text { causes reduction in B-1 } \\
\text { integrin expression and in } \\
\text { growth and migration. }\end{array}$ & {$[98]$} \\
\hline DAOY & Medulloblastoma & $\begin{array}{l}3 \mathrm{D}, \mu \text { Lane } \\
\text { microfluidics } \\
\text { system }\end{array}$ & $\begin{array}{l}\text { Quantitative and } \\
\text { qualitative analysis of } \\
\text { chemotactic response } \\
\text { of MB cells to a } \\
\text { gradient of EGF in a } \\
\text { microfluidic system. }\end{array}$ & Matrigel & $\begin{array}{l}\text { Matrigel invasion of MB } \\
\text { cells towards an EGF } \\
\text { gradient is blocked by } \\
\text { pharmacological PI3-K } \\
\text { inhibition. }\end{array}$ & [99] \\
\hline DAOY & Medulloblastoma & $\begin{array}{l}3 \mathrm{D} \text {, transwell } \\
\text { migration, } \\
\text { xCelligence } \\
\text { assay }\end{array}$ & $\begin{array}{l}\text { Quantitative analysis } \\
\text { of PDGFR control } \\
\text { of CXCR4 pro- } \\
\text { migratory signaling } \\
\text { in SHH MB model. }\end{array}$ & Matrigel & $\begin{array}{l}\text { PDGF signaling restricts } \\
\text { expression of negative } \\
\text { regulator GRK6 and } \\
\text { promotes CXCR4-Src- } \\
\text { dependent cell migration. }\end{array}$ & {$[100]$} \\
\hline $\begin{array}{l}\text { DAOY, UW228- } \\
3\end{array}$ & Medulloblastoma & $\begin{array}{l}\text { 3D confrontation } \\
\text { co-culture }\end{array}$ & $\begin{array}{l}\text { Quantification of } \\
\text { repulsive action of } \\
\text { Slit-Robo signaling } \\
\text { during MB invasion. }\end{array}$ & Collagen I & $\begin{array}{l}\text { Slit represses MB } \\
\text { invasion in collagen gels. }\end{array}$ & [101] \\
\hline DAOY & Medulloblastoma & $\begin{array}{l}2 \mathrm{D} / 3 \mathrm{D} \text { transwell } \\
\text { migration }\end{array}$ & $\begin{array}{l}\text { Evaluation of impact } \\
\text { of matricellular } \\
\text { SPAR on MB cell } \\
\text { migration and } \\
\text { invasion }\end{array}$ & Matrigel & $\begin{array}{l}\text { SPARC suppresses } \\
\text { migration and invasion } \\
\text { by repressing Rho- } \\
\text { GTPase activation } \\
\text { and by triggering Src- } \\
\text { dependent cytoskeleton } \\
\text { reorganization. }\end{array}$ & {$[45]$} \\
\hline DAOY, D283 & Medulloblastoma & $\begin{array}{l}\text { 2D spheroid } \\
\text { outgrowth, } \\
\text { 3D transwell } \\
\text { migration }\end{array}$ & $\begin{array}{l}\text { Comparison of } \\
\text { invasion and self- } \\
\text { renewal. Analysis } \\
\text { of higher versus } \\
\text { lower self-renewing } \\
\text { tumor spheres and } \\
\text { stationary versus } \\
\text { migrating adherent } \\
\text { MB cells with respect } \\
\text { to CD271 and CD133 } \\
\text { expression. }\end{array}$ & Collagen I & $\begin{array}{l}\text { Highly self-renewing } \\
\text { CD271 high, CD133 } \\
\text { low MB cell population } \\
\text { in the core sustains } \\
\text { tumorigenesis. } \\
\text { Commitment to } \\
\text { migration/invasion } \\
\text { (metastatic phenotype) } \\
\text { is identified by reduced } \\
\text { CD271 and increased } \\
\text { CD133 signature. }\end{array}$ & [102] \\
\hline
\end{tabular}

Overview of a selection of primary brain tumor studies that used 3D cell culture technologies. Ara-C: cytosine $\beta$-D-arabinofuranoside; CXCR4: CXC-motif-chemokine receptor 4; PERK: pancreatic endoplasmic reticulum kinase; EGF: epidermal growth factor; GBM: glioblastoma multiforme; GM-CSF: granulocyte-macrophage colony stimulating factor; GSCs: glioblastoma stem cells; GRK6: g-protein coupled receptor kinase 6; HA: hyaluronic acid; HAMA: methacrylated HA; HGF: hepatocyte growth factor; IDH1: isocitrate dehydrogenase 1; IFO: ifosfamide; MB: medulloblastoma; MMP: matrix metalloproteinase; PEG: polyethylene glycol; PDGFR: platelet-derived growth factor receptor; PI3-K: phosphoinositide 3'Kinase; RGD: 1-arginine, glycine, and L-aspartic acid; SAHA: suberoylanilide hydroxamic acid (or vorinostat a HDACi); SPARC: secreted protein acidic and rich in cysteine; Src: rous sarcoma kinase; TMZ: temozolomide; VEGF: vasculature endothelial growth factor; 2D/3D: two dimensional/three dimensional

model system: the system should mimic biophysical and chemical properties of the tissue environment (composition and stiffness of matrix, availability of growth factors, cytokines, metabolites) in a well controllable manner, the cells should be observable to increase output options (morphological analysis, use of fluorescent protein ${ }^{[53]}$ and dye 
sensors ${ }^{[54]}$ ) and it should have a high-throughput potential.

To understand the causes and consequences during pathophysiological progression from a primary neoplastic lesion in the brain towards a metastatic cancer and to preclinically test potential intervention strategies, we thus require model systems that mimic not only the proteomic heterogeneity of the tumor cell itself but also the reciprocal interactions between the tumor and the receiving brain tissue [Figure 2]. The following paragraph provides an overview over some recent approaches in primary brain tumor research. It highlights the difficulty to design an optimal, tumor-adapted system and emphasizes the need to further improve currently used systems.

\section{D and 3D model systems in primary brain tumor research}

A number of articles have been published in the last few years that used in vitro model systems to evaluate effects of novel potential treatment strategies on growth, viability or motile behavior of primary brain tumors [Table 1]. Ageneral consensus has been reached in that $3 \mathrm{D}$ cell culture model systems reflect the specifics of the in vivo situation better compared to $2 \mathrm{D}$ model systems. On the down side of this was the lack of high-throughput capability of 3D methods that hampered until a few years ago their broader use in combination with in screening approaches. A milestone in this context was the generation of spheroid cultures in 96 or even 384 well format from primary brain tumors that allowed the parallel testing or large sample sizes. ${ }^{[54-56]}$ In these studies, diagnostic dyes and fluorescent proteins were used individually or in combination for probing cellular functions on the one hand and for discriminating specific cell populations on the other hand. A general protocol describing the reproducible establishment and microscopy-based analysis of spheroid cultures using fluorescent protein quantification in high throughput was described recently. ${ }^{[57]}$ As an alternative to fluorometric readouts, electrochemical impedance spectroscopy was used to quantify different susceptibilities of $2 \mathrm{D}$ versus $3 \mathrm{D}$ spheroid culture of glioblastoma and neuroblastoma cell lines to cytotoxic compounds ${ }^{[58]}$ and to determine the therapeutic window of these compounds. Using different combination of dyes to separate subpopulation of cells grown in co-culture combined with diagnostic flow cytometry and two-photon microscopy allowed to further refine the selective output of 3D methods. ${ }^{[54]}$ However, high-throughput capabilities and accuracy of a selected read-out has to be carefully balanced and discriminating phenotypic differences at single cell level in 3D cultures in high throughput remains a formidable challenge.

\section{The impact of the embedding matrix on the behavior of the tumor cell}

The choice of the embedding matrix is of outmost importance for 3D cultures, in particularly for primary brain tumors that encounter in vivo mostly brain parenchyma and collagen-rich surfaces and structures in the subarachnoid space. ${ }^{[23,24,59]}$ Hence, the biophysical and chemical properties of the matrix should be adjusted to those in the location of growth and metastatic dissemination of the tumor under investigation. In this context, Fernandez-Fuente et al. ${ }^{[60]}$ investigated the impact of different environmental conditions on glioblastoma stem cells (GSCs). They found that GSCs grown in collagen-based 3D conditions were markedly less susceptible to receptor tyrosine kinase inhibition by currently available inhibitors, suggesting that oncogene addiction of tumor cells could also be bypassed by adhesion signaling. ${ }^{61]}$ Interestingly, matrix stiffness or the addition of hyaluronic acid (HA) did not affect the sensitivity of the GSCs in this study. Primary cells from glioma patient tumor material exposed to increasing concentrations of HA responded with rounded morphology and reduced migration, suggesting that HA concentrations may affect glioma cell behavior. ${ }^{[62]}$ Consistently, addition of HA to porous chitosan scaffolds ${ }^{[63]}$ or to artificial hydrogels ${ }^{[64]}$ increased the expression of stem cell markers and VEGF and HIF-1, respectively. However, the finding that increasing matrix stiffness - by adding agarose to a collagen I matrix - blocks glioma invasiveness, ${ }^{[19]}$ suggested that stiffness alone and independent of ligand binding acted as a critical determinant for primary brain tumor cell function. An improved in vitro environment for brain tumor research would consist of neuronal and brain-resident interstitial cells that secrete the brain-specific ECM components into which the brain tumor cells can then be implanted. Such an environment was established from brain tissue extracts on micro filters (Hi-spots) on which GBM cell sensitivity to anti-proliferative compounds was tested. ${ }^{[65]}$ Despite its high-throughput potential, a setback of this method is the lack of control over the cellular composition in the Hi-spots and the absence of brain-specific architectural organization. A while ago, a simple but intriguing co-culture model of medulloblastoma and leptomeningeal cells was published, and it indicated paracrine, growth-promoting effects of latter that might be instrumental for studying the notoriously difficult to grow primary tumor cells in vitro. ${ }^{[66]}$ The ideal "organotypic environment" for primary brain tumor research was already in development in the early seventies of the last century, when the organotypic brain slice culture (OBSC) technology was established. ${ }^{[67]}$ The advantages of OBSCs are that micro environmental parameters and a relatively correct architectural organization are maintained that mimic the in vivo situation (see below).

\section{Increasing complexity: system impact and single cell behavior}

Neither are tumor functions disconnected from other tissues and the organs nor can the impact of tissues or organs on drug efficacy in the targeted tumor be predicted. An interesting approach to evaluate the effect of metabolic activity on cytotoxicity of compounds and chemotherapeutics in vitro was tested by $\mathrm{Ma}$ and colleagues using a 3D micro-tissue perfusion system. ${ }^{[68]} \mathrm{TMZ}$ and IFO were perfused through hepatocytes before exposure to GBM cells and a clear impact of hepatocyte-provided cytochrome P450 on IFO activation could be shown. Analogous experimental follow- 
ups are a number of organ on a chip technologies that are currently developed for assaying different disease states ${ }^{[69]}$ and testing drug effects and metabolization. ${ }^{[70]}$

On the opposite side of the spectrum is the need to resolve the mechanisms underlying brain infiltration of single tumor cells, which necessitates approaches allowing the quantitative analysis of molecular events in individual cells. This problem was tackled for the activation status of the important Rho family GTPase's - Rho, Rac and Cdc42 - in glioma cells. ${ }^{[53]}$ Hirata et al. ${ }^{[53]}$ used Rho-GTPaseFRET (Förster energy resonance transfer) probes, where spatial activation of the GTPase's was monitored by a shift in fluorescence signal. Rho-family GTPase-FRET fusion protein-expressing glioma cells were orthotopically implanted in rat brains and later analyzed inside brain slice cultures derived of these brains using two-photo microscopy. This study revealed higher Rac1 and Cdc42 and lower RhoA activities in glioblastoma cells penetrating the brain parenchyma than those advancing in the perivascular regions, and suggested that different driver mechanisms could exist for single cell dispersion in glioma.

Together, these studies highlight the need for adapting the model system to the specifics of the biological context, with the consequent inclusion of biophysical or chemical components that best reflect the in vivo situation. Besides high-throughput screening platforms for the identification of novel pro-metastatic key players or alternative interference strategies against metastatic dissemination, we also need improved phenotype-based single cell analysis to decipher clonal differences and micro environmental impact on tumor behavior at the single cell level.

\section{Organotypic brain slice culture (OBSC) in primary brain tumor research}

A number of causal gene(s) and associated genetic mutations, molecular changes, probable targets and treatments for a variety of primary brain tumors have been identified. Despite of this, the process of dissemination, metastasis of the tumor cells from the primary site, and tumor recurrence, which is the leading cause for brain tumor related mortality in patients, remain obscure. Total removal of the primary tumor is on many occasions impossible at the microscopic level due to the insidious infiltration of the tumor cells into the surrounding brain tissue. ${ }^{[71]}$ This majorly results in therapeutic failure and urges for model systems that allow addressing brain tumor cell invasion specifically. Standard $3 \mathrm{D}$ in vitro invasion assays use ECM macromolecules that mimic the basement membrane (e.g. matrigel) as barriers to tumor invasion. These assays (described above and in table 1) although quick, reliable, commercially available and easy to perform, have several limitations. They do not take into account the unique ECM composition in the brain and thus provide artificial environments that fail to closely mimic the normal brain tissue/tumor environment. This is further emphasized by the fact that distinct types of brain tumors localize within specific regions of the brain, highlighting the need for different microenvironments for modeling tumor growth and invasiveness. To circumvent this, mouse models have been generated for studying tumor propagation via orthotopic or subcutaneous xenografting of tumor cells. These experiments, however, are ethically controversial if inappropriately conducted, costly, labor intensive and need lengthy time periods for animal surgery and subsequent tumor development (especially for low grade tumors). These challenges and limitations highlight the need for developing a novel system wherein living brain tissue can be used as an ideal matrix for studying tumor cell growth and invasion. ${ }^{\text {[72] }}$ One such system is the organotypic culture, where cellular constituents of organs or parts of organs are allowed to regrow into or persist as organ replacements.

An excellent overview of 3D organotypic cultures has recently been provided, ${ }^{[73]}$ which describes their potentials as experimental systems to visualize cellular mechanisms that drive tissue development, to study the genetic regulation of cell behaviors in tissues and to evaluate the role of micro environmental factors in normal development and disease. One hallmark of organotypic cultures is the tissue environment mimicking the structural and functional specifics of the organ of origin. This turns them into attractive models for cancer research to explore tumor host tissue interactions and to advance therapeutic approaches.

\section{Organotypic brain slice culture for visualization and quantification of brain tumor cell dissemination}

OBSCs allow culture, maintenance and long-term survival of sections from any tissue of the CNS. Slices are mostly cultured at an air/liquid interface by either continuous rotation using the roller tube method or on a semi porous membrane using the Stoppini method. ${ }^{[74]}$ Brain tissue slice cultures maintain their normal cytoarchitecture, complex cell relationships and biochemical and electrophysiological properties. OBSCs have been widely used in the field of neurobiology for synaptogenesis, neurogenesis, myelin formation, as models for studying neurodegeneration, for neuroprotective and neurotoxic assays, etc. ${ }^{[67]}$ In the field of brain tumor research, they are an ideal platform to access the tumor microenvironment under intact anatomical conditions. Indeed, Jung et al. ${ }^{[71]}$ established a brain tumor slice model wherein they used human white matter specimens in the upper chambers of transwell culture dishes. After $24 \mathrm{~h}$, control human astrocytoma cells stably expressing enhanced GFP or GFP-RHAMM (receptor for hyaluronan-mediated motility) transfected astrocytoma cells were placed in a small centrally punched-out hole in the slice. The infiltration and migratory behavior of the GFP-expressing astrocytoma cells could be easily studied using confocal laser scanning microscopy (CF-LSM) up to 30 days post implantation. The authors were able to demonstrate that different astrocytoma cell lines display different degrees of invasion and that the migration of the human astrocytoma cells could be 
stimulated or, using antisense targeting strategies, specifically blocked. ${ }^{[71]}$ In an analogous study it was demonstrated that (1) the invasive behavior of the astrocytoma cells in the brain slice co-culture is not always identical to the results obtained from 2D migration studies, (2) the tumor cells spread out multidirectionally, (3) frozen human normal brain tissue can be used for the organotypic culture, (4) there were no obvious signs of necrosis, and (5) the brain cytoarchitecture and viability was preserved for at least 14 days. ${ }^{[72]}$

Although the human origin of the biopsies used as the host tissue in these studies excludes species-specific effects in the co-culture, slices from newborn rat or mouse brains are excellent alternatives. They offer several advantages: brain regions corresponding to the in vivo tumor localization can be chosen, developmental stage of the brain slice can be adjusted, multiple replicas from same brain region can be generated, and the use of transgenic animals allows modification of the cellular microenvironment. Ohnishi et al. ${ }^{[75]}$ established OBSCs from 2-day-old neonatal rat brains, which were transferred on double-layered membranes consisting of two different membrane types and maintained at an interface between the air and the culture medium. The slices were then co-cultured with $\mathrm{C} 6$ glioma cells labeled with $\mathrm{PKH} 2$ fluorescent dye. After 2 days of co-culture, the exogenous application of the chemotactic stimulator neural cell adhesion molecule L1 triggered tumor cell migration from the upper to the bottom membrane through the brain slice. ${ }^{[75]}$ Since this study lacked CF-LSM analysis, OBSCs were subsequently performed by the slightly modified Stoppini method, which allowed quantifying glioma cell invasion using confocal microscopy. ${ }^{[76]}$ This study revealed that the migrating cells showed a strong increase in immunoreactivity for matrix metalloproteinase 2 and 9. ${ }^{[76]}$ Analogous OBSC technology was later used for mouse brain slices to quantify the invasiveness of glioma ${ }^{[77]}$ and to correlate it with histological type ${ }^{[78]}$ Both studies used human, DiI-stained glioma biopsy tumor fragments and GFP-expressing spheroids directly implanted in the cortex of brain slices derived from 7 day old mice. This intraslice implantation system could be maintained in culture for 2 to 4 weeks. Quantification of the distance and density of the tumor cell invasion revealed that GBMs were 2-4 times more invasive than the lower grade glioma cells (LGGs). Within the different groups and grades of GBMs and LGGs, heterogeneity in terms of invasion was seen. It was also observed that the spheroids were less invasive in comparison to the directly grafted fragments. Overall using this system, Palfi et al. ${ }^{[77,78]}$ and de Bouard et al. ${ }^{[77]}$ could successfully recapitulate, monitor and quantify the invasion of single cells and the dissemination of glioma ex vivo. Recently, Chadwick et al. ${ }^{[79]}$ developed OBSCs from postnatal day 6 mice and cultured the whole brain slices on membrane inserts coated with laminin. Tumor cells (astrocytoma and medulloblastoma) were stained with $\mathrm{Cm}$-DiI for monitoring, and dispensed on the center of the slice. This co-culture system remained viable for one week and effects of drug therapies on tumor cell proliferation, cell death or changes in protein expression were successfully analyzed. Thus, Chadwick et al. ${ }^{[79]}$ used the OBSC system as a qualitative and quantitative assay to calculate the fold change in the number of cells during the period of slice culture. Furthermore, they investigated either the whole brain or specific regions within the brain, to assess environmental impact on primary brain tumor cell growth.

\section{Organotypic brain slice culture to study the microenvironmental impact}

Malignant astrocytoma/GBM cause mortality by local tumor growth and brain invasion rather than systemic metastasis. GBM tumor cells diffusely infiltrate the brain parenchyma within and along the white matter tracts or around cerebral blood vessels, ${ }^{[53]}$ and rarely penetrate basal lamina structures at the glial limitans externa. Analogously, malignant medulloblastoma must also infiltrate cerebellar tissue for distal dissemination. Moreover, resection of MB tumors is inevitably followed by relapse if the patients are not treated with cranio-spinal radiotherapy and chemotherapy, suggesting the occurrence of local dissemination of tumor cells from the primary medulloblastoma. In vitro studies aiming at better understanding the local invasion process have been hampered by the lack of identification of the brain ECM macromolecules involved and the only poorly understood implication of the cellular microenvironment. In vivo approaches on the other hand, offer too little spatial and temporal resolution to monitor tumor-microenvironment interactions appropriately. Thus, OBSCs could provide an important platform to study the cross-talk between the tumor cells and normal cells in a physiologically relevant environment. OBSCs can be used for investigating the microenvironment and its impact on the growth and spread of primary brain tumors, and for testing the measures that could be taken to prevent or treat it effectively. ${ }^{[79]}$ Although, there is a lack of vascular supply to the tissue in the slices, capillaries do survive in these sections without any circulation. ${ }^{[80]}$ Despite of the fact that there is no blood flow and that the capillaries are not functional, it is likely that they are still capable of expressing and secreting various molecules, ${ }^{[81]}$ which could affect other cell types in the slice culture including the tumor cells. In addition, the intriguing exchange between tumor cells and astrocytes and the suspected tumor promoting functions of astrocytes ${ }^{[41-43]}$ urges for novel studies addressing the therapeutic potential of the astrocyte-tumor interaction, for which organotypic slice culture would be an ideal system.

Along with their use for monitoring tumor dissemination, OBSCs have also been used for high resolution imaging of cytoskeletal structures in living glioblastoma cells. For this, glioblastoma cells were transfected with GFP-actin and placed onto murine brain slices and spinal cord explants. Using live-cell imaging to visualize the cytoskeleton of the tumor cells, a major change in the gross morphology from a solid, two dimensional state to a three dimensional substrate was noted. This morphological change was characterized by long, dendritic-like processes that displayed regions 
of ruffling activity and filopodial protrusions and by down regulation of stress-fibers. ${ }^{[82]}$

Thus, OBSC is an excellent technology to address a wide range of topics in primary brain tumor research, ranging from growth- and dissemination-promoting signaling, to the intricate interrelations between the tumor and its surrounding host tissue to the evaluation of efficaciousness of novel targeting strategies.

\section{FUTURE PERSPECTIVES}

Main emphasis for improving current in vitro technologies should be given to the cellular composition and the biophysical and chemical environment conditions under which the experiment is performed. The microenvironment of the in vivo location of the tumor and the composition of the neuronal and interstitial cells resident in this location should guide the choice of the components. At the single cell and population levels, molecular sensors for specific cell functions should be used for probing tumor cell behavior and therapeutic efficacy. Finally, an increased output should be strived for to enable pharmacological and genetic screening approaches for drug target identification. Thus, an organotypic environment, specific read-outs and the high throughput capability will be the three pillars of future in vitro approaches. A great potential lies in organotypic slice culture, and when this technology is combined with state-of-the-art microscopy, it will allow to reveal fundamental aspects of local tumor cell infiltration, the interaction of neuronal and brain interstitial cell populations with the tumor cells and the evaluation of the efficaciousness of novel treatments.

\section{Financial support and sponsorship}

A.N. is supported by a grant of the Werner and Hedy Berger-Janser Foundation, M.B. by the Childhood Cancer Research Foundation Switzerland.

\section{Conflicts of interest}

There are no conflicts of interest.

\section{REFERENCES}

1. Taylor MD, Northcott PA, Korshunov A, Remke M, Cho YJ, Clifford SC Eberhart CG, Parsons DW, Rutkowski S, Gajjar A, Ellison DW, Lichter P, Gilbertson RJ, Pomeroy SL, Kool M, Pfister SM. Molecular subgroups of medulloblastoma: the current consensus. Acta neuropathol 2012;123:465-72.

2. NorthcottPA, Shih DJ, Peacock J, Garzia L, Morrissy AS, Zichner T, Stütz AM, Korshunov A, Reimand J, Schumacher SE, Beroukhim R, Ellison DW, Marshall CR, Lionel AC, Mack S, Dubuc A, Yao Y, Ramaswamy V, Luu B, Rolider A, Cavalli FM, Wang X, Remke M, Wu X, Chiu RY, Chu A, Chuah E, Corbett RD, Hoad GR, Jackman SD, Li Y, Lo A, Mungall KL, Nip KM, Qian JQ, Raymond AG, Thiessen NT, Varhol RJ, Birol I, Moore RA, Mungall AJ, Holt R, Kawauchi D, Roussel MF, Kool M, Jones DT, Witt H, Fernandez-LA, Kenney AM, Wechsler-Reya RJ, Dirks P, Aviv T, Grajkowska WA, Perek-Polnik M, Haberler CC, Delattre O, Reynaud SS, Doz FF, Pernet-Fattet SS, Cho BK, Kim SK, Wang KC, Scheurlen W, Eberhart CG, Fèvre-Montange M, Jouvet A, Pollack IF, Fan X, Muraszko KM, Gillespie GY, Di Rocco C, Massimi L, Michiels EM, Kloosterhof NK, French PJ, Kros JM, Olson JM, Ellenbogen RG, Zitterbart K, Kren L, Thompson RC, Cooper MK, Lach B, McLendon
RE, Bigner DD, Fontebasso A, Albrecht S, Jabado N, Lindsey JC, Bailey S, Gupta N, Weiss WA, Bognár L, Klekner A, Van Meter TE, Kumabe T, Tominaga T, Elbabaa SK, Leonard JR, Rubin JB, Liau LM, Van Meir EG, Fouladi M, Nakamura H, Cinalli G, Garami M, Hauser P, Saad AG, Iolascon A, Jung S, Carlotti CG, Vibhakar R, Ra YS, Robinson S, Zollo M, Faria CC, Chan JA, Levy ML, Sorensen PH, Meyerson M, Pomeroy SL, Cho YJ, Bader GD, Tabori U, Hawkins CE, Bouffet E, Scherer SW, Rutka JT, Malkin D, Clifford SC, Jones SJ, Korbel JO, Pfister SM, Marra MA, Taylor MD. Subgroup-specific structural variation across 1,000 medulloblastoma genomes. Nat 2012;488: 49-56.

3. Northcott PA, A Korshunov, H Witt H, Hielscher T, Eberhart CG, Mack S, Bouffet E, Clifford SC, Hawkins CE, French P, Rutka JT, Pfister S, Taylor MD Medulloblastoma comprises four distinct molecular variants. J Clin Oncol 2011;29:1408-14.

4. Kool M, Koster J, Bunt J, Hasselt NE, Lakeman A, van Sluis P, Troost D, Meeteren NS, Caron HN, Cloos J, Mrsić A, Ylstra B, Grajkowska W, Hartmann W, Pietsch T, Ellison D, Clifford SC, Versteeg R. Integrated genomics identifies five medulloblastoma subtypes with distinct genetic profiles, pathway signatures and clinicopathological features. PLoS One 2008;3:e3088.

5. Thompson MC, Fuller C, Hogg TL, Dalton J, Finkelstein D, Lau CC, Chintagumpala M, Adesina A, Ashley DM, Kellie SJ, Taylor MD, Curran T, Gajjar A, Gilbertson RJ. Genomics identifies medulloblastoma subgroups that are enriched for specific genetic alterations. J Clin Oncol 2006;24:1924-31.

6. Wang X, Dubuc AM, Ramaswamy V, Mack S, Gendoo DM, Remke M, Wu X, Garzia L, Luu B, Cavalli F, Peacock J, López B, Skowron P, Zagzag D, Lyden D, Hoffman C, Cho YJ, Eberhart C, MacDonald T, Li XN, Van Meter T, Northcott PA, Haibe-Kains B, Hawkins C, Rutka JT, Bouffet E, Pfister SM, Korshunov A, Taylor MD. Medulloblastoma subgroups remain stable across primary and metastatic compartments. Acta neuropathol 2015;129:449-57.

7. Angers-Loustau A, Hering R, Werbowetski TE, Kaplan DR, Del Maestro $\mathrm{RF}$. SRC regulates actin dynamics and invasion of malignant glial cells in three dimensions. Mol Cancer Res 2004;2:595-605.

8. Le PU, Angers-Loustau A, de Oliveira RM, Ajlan A, Brassard CL, Dudley A, Brent H, Siu V, Trinh G, Mölenkamp G, Wang J, Seyed Sadr M, Bedell B, Del Maestro RF, Petrecca K. DRR drives brain cancer invasion by regulating cytoskeletal-focal adhesion dynamics. Oncogene 2010;29:4636-47.

9. Santhana Kumar K, Tripolitsioti D, Ma M, Grahlert J, Egli KB, Fiaschetti G, Shalaby T, Grotzer MA, Baumgartner M. The Ser/Thr kinase MAP4K4 drives c-Met-induced motility and invasiveness in a cell-based model of SHH medulloblastoma. SpringerPlus 2015;4:19.

10. Rottner K, Stradal TE. Actin dynamics and turnover in cell motility. Curr Opin Cell Biol 2011;23:569-78.

11. Hall A. The cytoskeleton and cancer. Cancer Metastasis Rev 2009;28:514.

12. Nurnberg A, Kitzing T, Grosse R. Nucleating actin for invasion. Nat Rev Cancer 2011;11:177-87.

13. Giese A, Bjerkvig R, Berens ME, Westphal M. Cost of migration: invasion of malignant gliomas and implications for treatment. $J$ Clin Oncol 2003;21:1624-36.

14. Waclaw B, Bozic I, Pittman ME, Hruban RH, Vogelstein B, Nowak MA. A spatial model predicts that dispersal and cell turnover limit intratumour heterogeneity. Nat 2015;525:261-4.

15. Palmer TD, Ashby WJ, Lewis JD, Zijlstra A. Targeting tumor cell motility to prevent metastasis. AdvDrug Deliv Rev 2011;63:568-81.

16. Vehlow A, Cordes N. Invasion as target for therapy of glioblastoma multiforme. Biochim Biophys Acta 2013;1836:236-44.

17. Wells A, Grahovac J, Wheeler S, Ma B, Lauffenburger D. Targeting tumor cell motility as a strategy against invasion and metastasis. Trends Pharmacol Sci 2013;34:283-9.

18. Wolf K, Friedl P. Extracellular matrix determinants of proteolytic and non-proteolytic cell migration. Trends Cell Biol 2011;21:736-44.

19. Ulrich TA, Jain A, Tanner K, MacKay JL, Kumar S. Probing cellular mechanobiology in three-dimensional culture with collagen-agarose matrices. Biomaterials 2010;31:1875-84.

20. Friedl P, Wolf K. Plasticity of cell migration: a multiscale tuning model. $J$ 
Cell Biol 2010;188:11-19.

21. Cox TR, Erler JT. Remodeling and homeostasis of the extracellular matrix: implications for fibrotic diseases and cancer. Dis Model Mech 2011;4:165-78.

22. Rusert JM, Wu X, Eberhart CG, Taylor MD, Wechsler-Reya RJ. SnapShot: Medulloblastoma. Cancer Cell 2014;26:940-40.e1.

23. Brochner CB, Holst CB, Mollgard K. Outer brain barriers in rat and human development. Front Neurosci 2015;9:75.

24. Saboori P, Sadegh A. Histology and Morphology of the Brain Subarachnoid Trabeculae. Anat Res Int 2015;2015:279814.

25. Zimmermann DR, Dours-Zimmermann MT. Extracellular matrix of the central nervous system: from neglect to challenge. Histochem Cell Biol 2008;130:635-53.

26. Zurn AD, Bandtlow CE. Regeneration failure in the CNs: cellular and molecular mechanisms. Adv Exp Med Biol 2006;557:54-76.

27. Morgenstern DA, Asher RA, Fawcett JW. Chondroitin sulphate proteoglycans in the CNS injury response. Prog Brain Res 2002;137:31332.

28. Jones EV, Bouvier DS. Astrocyte-secreted matricellular proteins in CNS remodelling during development and disease. Neural Plast 2014;2014:321209.

29. Klekner A, Hutoczki G, Virga J, Remenyi-Puskar J, Toth J, Scholtz B, Csősz É, Kalló G, Steiner L, Hortobágyi T, Bognár L. Expression pattern of invasion-related molecules in the peritumoral brain. Clin Neurol Neurosurg 2015;139: 138-43.

30. Ulrich TA, de Juan Pardo EM, Kumar S. The mechanical rigidity of the extracellular matrix regulates the structure, motility, and proliferation of glioma cells. Cancer Res 2009;69:4167-74.

31. Kim SN, Jeibmann A, Halama K, Witte HT, Walte M, Matzat T, Schillers H, Faber C, Senner V, Paulus W, Klämbt C. ECM stiffness regulates glial migration in Drosophila and mammalian glioma models. Dev 2014;141:3233-42.

32. Rao SS, Bentil S, DeJesus J, Larison J, Hissong A, Dupaix R, Sarkar A, Winter JO. Inherent interfacial mechanical gradients in 3D hydrogels influence tumor cell behaviors. PLoS One 2012; 7:e35852

33. Kim Y, Kumar S. CD44-mediated adhesion to hyaluronic acid contributes to mechanosensing and invasive motility. Mol Cancer Res 2014;12:141629

34. Dvorak HF. Tumors: Wounds That Do Not Heal--Redux. Cancer Imunnol Res 2015;3:1-11.

35. Halliday JJ, Holland EC. Connective tissue growth factor and the parallels between brain injury and brain tumors. J Natl Cancer Inst 2011;103:1141-

36. Yang I, Han SJ, Kaur G, Crane C, Parsa AT. The role of microglia in central nervous system immunity and glioma immunology. J Clin Neurosci 2010;17:6-10.

37. Charles NA, Holland EC, Gilbertson R, Glass R, Kettenmann H. The brain tumor microenvironment. Glia 2011;59:1169-80.

38. Kerber M, Reiss Y, Wickersheim A, Jugold M, Kiessling F, Heil M, Tchaikovski V, Waltenberger J, Shibuya M, Plate KH, Machein MR. Flt1 signaling in macrophages promotes glioma growth in vivo. Cancer Res 2008;68:7342-51.

39. Strik HM, Stoll M, Meyermann R. Immune cell infiltration of intrinsic and metastatic intracranial tumours. Anticancer Res 2004;24:37-42.

40. Margol AS, Robison NJ, Gnanachandran J, Hung LT, Kennedy RJ, Vali M Dhall G, Finlay JL, Erdreich-Epstein A, Krieger MD, Drissi R, Fouladi M, Gilles FH, Judkins AR, Sposto R, Asgharzadeh S. Tumor-associated macrophages in $\mathrm{SHH}$ subgroup of medulloblastomas. Clin Cancer Res 2015;21:1457-65.

41. Placone AL, Quinones-Hinojosa A, Searson PC. The role of astrocytes in the progression of brain cancer: complicating the picture of the tumor microenvironment. Tumour Biol 2015.

42. Kim JK, Jin X, Sohn YW, Jin X, Jeon HY, Kim EJ, Ham SW, Jeon HM, Chang SY, Oh SY, Yin J, Kim SH, Park JB, Nakano I, Kim H. Tumoral RANKL activates astrocytes that promote glioma cell invasion through cytokine signaling. Cancer Lett 2014;353:194-200.

43. Rath BH, Fair JM, Jamal M, Camphausen K, Tofilon PJ. Astrocytes enhance the invasion potential of glioblastoma stem-like cells. PLoS One 2013;8:e54752.
44. Huang H, Colella S, Kurrer M, Yonekawa Y, Kleihues P, Ohgaki H. Gene expression profiling of low-grade diffuse astrocytomas by cDNA arrays. Cancer Res 2000;60:6868-74.

45. Bhoopathi P, Gondi CS, Gujrati M, Dinh DH, Lakka SS. SPARC mediates Src-induced disruption of actin cytoskeleton via inactivation of small GTPases Rho-Rac-Cdc42. Cell Signal 2011;23:1978-87.

46. Edwards LA, Woolard K, Son MJ, Li A, Lee J, Ene C, Mantey SA, Maric D, Song H, Belova G, Jensen RT, Zhang W, Fine HA. Effect of brain- and tumor-derived connective tissue growth factor on glioma invasion. J Natl Cancer Inst 2011;103:1162-78.

47. Klein A, Schwartz H, Sagi-Assif O, Meshel T, Izraely S, Ben Menachem S, Bengaiev R, Ben-Shmuel A, Nahmias C, Couraud PO, Witz IP, Erez N. Astrocytes facilitate melanoma brain metastasis via secretion of IL-23. J Pathol 2015;236 116-27.

48. Zimmermann M, Box C, Eccles SA. Two-dimensional vs. threedimensional in vitro tumor migration and invasion assays. Methods $\mathrm{Mol}$ Biol 2013;986:227-52.

49. Matsusaki M, Case CP, Akashi M. Three-dimensional cell culture technique and pathophysiology. Adv Drug Deliv Rev 2014;74:95-103.

50. Astashkina A, Grainger DW. Critical analysis of 3-D organoid in vitro cell culture models for high-throughput drug candidate toxicity assessments. Ad Drug Deliv Rev 2014;69-70:1-18.

51. Weigelt B, Ghajar CM, Bissell MJ. The need for complex 3D culture models to unravel novel pathways and identify accurate biomarkers in breast cancer. Ad Drug Deliv Rev 2014;69-70:42-51.

52. Thoma CR, Zimmermann M, Agarkova I, Kelm JM, Krek W. 3D cell culture systems modeling tumor growth determinants in cancer target discovery. Ad Drug Deliv Rev 2014;69-70:29-41.

53. Hirata E, Yukinaga H, Kamioka Y, Arakawa Y, Miyamoto S, Okada T, Sahai E, Matsuda M. In vivo fluorescence resonance energy transfer imaging reveals differential activation of Rho-family GTPases in glioblastoma cell invasion. J Cell Sci 2012;125:858-68.

54. Ivanov DP, Parker TL, Walker DA, Alexander C, Ashford MB, Gellert $\mathrm{PR}$, Garnett MC. In vitro co-culture model of medulloblastoma and human neural stem cells for drug delivery assessment. $J$ Biotechnol 2015;205:3-13.

55. Morfouace M, Shelat A, Jacus M, Freeman BB, 3rd, Turner D, Robinson S, Zindy F, Wang YD, Finkelstein D, Ayrault O, Bihannic L, Puget S, Li XN, Olson JM, Robinson GW, Guy RK, Stewart CF, Gajjar A, Roussel MF. Pemetrexed and gemcitabine as combination therapy for the treatment of Group3 medulloblastoma. Cancer Cell 2014;25:516-29.

56. Kumar KS, Pillong M, Kunze J, Burghardt I, Weller M, Grotzer MA, Schneider G, Baumgartner M. Computer-assisted quantification of motile and invasive capabilities of cancer cells. Sci Rep 2015;5:15338.

57. Ansari N, Muller S, Stelzer EH, Pampaloni F. Quantitative 3D cell-based assay performed with cellular spheroids and fluorescence microscopy. Methods Cell Biol 2013;113:295-309.

58. Eichler M, Jahnke HG, Krinke D, Muller A, Schmidt S, Azendorf R, Robitzki AA. A novel 96-well multielectrode array based impedimetric monitoring platform for comparative drug efficacy analysis on $2 \mathrm{D}$ and $3 \mathrm{D}$ brain tumor cultures. Biosens Bioelectron 2015;67:582-9.

59. Gritsenko $P G$, Ilina $O$, Friedl P. Interstitial guidance of cancer invasion. $J$ Pathol 2012;226:185-99.

60. Fernandez-Fuente G, Mollinedo P, Grande L, Vazquez-Barquero A, Fernandez-Luna JL. Culture dimensionality influences the resistance of glioblastoma stem-like cells to multikinase inhibitors. Mol Cancer Ther 2014;13:1664-72.

61. Pagliarini R, Shao W, Sellers WR. Oncogene addiction: pathways of therapeutic response, resistance, and road maps toward a cure. $E M B O$ Rep 2015;16:280-296.

62. Rao S, DeJesus J, Short AR, Otero JJ, Sarkar A, Winter JO. Glioblastoma Behaviors in Three-Dimensional Collagen-Hyaluronan Composite Hydrogels. ACS Appl Mate Interfaces 2013;5:9276-84.

63. Florczyk SJ, Wang K, Jana S, Wood DL, Sytsma SK, Sham JG, Kievit FM, Zhang M. Porous chitosan-hyaluronic acid scaffolds as a mimic of glioblastoma microenvironment ECM. Biomaterials 2013;34:10143-50.

64. Pedron S, Becka E, Harley BA. Regulation of glioma cell phenotype in 3D matrices by hyaluronic acid. Biomaterials 2013;34:7408-17.

65. Biggs T, Foreman J, Sundstrom L, Regenass U, Lehembre F. Antitumor 
compound testing in glioblastoma organotypic brain cultures. J Biomol Screening 2011;16:805-17.

66. Rutka JT, Dougherty DV, Giblin JR, Edwards MS, McCulloch JR, Rosenblum ML. Growth of a medulloblastoma on normal leptomeningeal cells in culture: interaction of tumor cells and normal cells. Neurosurgery 1987;21:872-8

67. Humpel C. Organotypic brain slice cultures: A review. Neurosci 2015; 305:86-98.

68. Ma L, Barker J, Zhou C, Li W, Zhang J, Lin B, Foltz G, Küblbeck J, Honkakoski P. Towards personalized medicine with a three-dimensional micro-scale perfusion-based two-chamber tissue model system. Biomaterials 2012;33:4353-61.

69. Huh D, Hamilton GA, Ingber DE. From 3D cell culture to organs-onchips. Trends Cell Biol 2011;21:745-54.

70. Ghaemmaghami AM, Hancock MJ, Harrington $H$, Kaji $H$, Khademhosseini A. Biomimetic tissues on a chip for drug discovery. Drug Discov Today 2012;17:173-81.

71. Jung S, Ackerley C, Ivanchuk S, Mondal S, Becker LE, Rutka JT. Tracking the invasiveness of human astrocytoma cells by using green fluorescent protein in an organotypical brain slice model. $J$ Neurosurg 2001;94:80-9.

72. Jung S, Kim HW, Lee JH, Kang SS, Rhu HH, Jeong YI, Yang SY, Chung HY, Bae CS, Choi C, Shin BA, Kim KK, Ahn KY. Brain tumor invasion model system using organotypic brain-slice culture as an alternative to in vivo model. J Cancer Res Clin Oncol 2002;128:469-76.

73. Shamir ER, Ewald AJ. Three-dimensional organotypic culture: experimental models of mammalian biology and disease. Nat Rev Mol Cell Biol 2014;15:647-64

74. Stoppini L, Buchs PA, Muller D. A simple method for organotypic cultures of nervous tissue. J Neurosci Methods 1991;37:173-82.

75. Ohnishi T, Matsumura H, Izumoto S, Hiraga S, Hayakawa T. A novel model of glioma cell invasion using organotypic brain slice culture. Cancer Res 1998;58:2935-40.

76. Matsumura H, Ohnishi T, Kanemura Y, Maruno M, Yoshimine T. Quantitative analysis of glioma cell invasion by confocal laser scanning microscopy in a novel brain slice model. Biochem Biophys Res Commun 2000;269:513-20.

77. de Bouard S, Christov C, Guillamo JS, Kassar-Duchossoy L, Palfi S, Leguerinel C, Masset M, Cohen-Hagenauer O, Peschanski M, Lefrançois T. Invasion of human glioma biopsy specimens in cultures of rodent brain slices: a quantitative analysis. J Neurosurg 2002;97:169-76.

78. Palfi S, Swanson KR, De Bouard S, Chretien F, Oliveira R, Gherardi RK, Kros JM, Peschanski M, Christov C. Correlation of in vitro infiltration with glioma histological type in organotypic brain slices. $\mathrm{Br} J$ Cancer 2004:91:745-52

79. Chadwick EJ, Yang DP, Filbin MG, Mazzola E, Sun Y, Behar O, Pazyra-Murphy MF, Goumnerova L, Ligon KL, Stiles CD, Segal RA. A brain tumor/organotypic slice co-culture system for studying tumor microenvironment and targeted drug therapies. J Vis Exp 2015; 53304.

80. Moser KV, Schmidt-Kastner R, Hinterhuber H, Humpel C. Brain capillaries and cholinergic neurons persist in organotypic brain slices in the absence of blood flow. Eur J Neurosci 2003;18:85-94.

81. Hutter-Schmid B, Kniewallner KM, Humpel C. Organotypic brain slice cultures as a model to study angiogenesis of brain vessels. Front Cell Dev Biol 2015;3:52.

82. Caspani EM, Echevarria D, Rottner K, Small JV. Live imaging of glioblastoma cells in brain tissue shows requirement of actin bundles for migration. Neuron Glia Biol 2006;2:105-14.

83. Baskin R, Woods NT, Mendoza-Fandino G, Forsyth P, Egan KM, Monteiro AN. Functional analysis of the 11q23.3 glioma susceptibility locus implicates PHLDB1 and DDX6 in glioma susceptibility. Sci Rep 2015;5:17367.

84. Kessler J, Guttler A, Wichmann H, Rot S, Kappler M, Bache M, Vordermark D. IDH1(R132H) mutation causes a less aggressive phenotype and radiosensitizes human malignant glioma cells independent of the oxygenation status. Radiother Oncol 2015;116:381-7.

85. Jung JH, Kim AA, Chang DY, Park YR, Suh-Kim H, Kim SS. Threedimensional assessment of bystander effects of mesenchymal stem cells carrying a cytosine deaminase gene on glioma cells. Am J Cancer Res
$2015 \cdot 5 \cdot 2686-96$

86. Smith SJ, Ward JH, Tan C, Grundy RG, Rahman R. Endothelial-like malignant glioma cells in dynamic three dimensional culture identifies a role for VEGF and FGFR in a tumor-derived angiogenic response. Oncotarget 2015;6:22191-205.

87. Huang M, Ke Y, Sun X, Yu L, Yang Z, Zhang Y, Du M, Wang J, Liu X, Huang S. Mammalian target of rapamycin signaling is involved in the vasculogenic mimicry of glioma via hypoxia-inducible factor-1alpha. Oncol Rep 2014;32:1973-80.

88. Boutin ME, Hoffman-Kim D. Application and assessment of optical clearing methods for imaging of tissue-engineered neural stem cell spheres. Tissue Eng Part C Methods 2015;21:292-302.

89. He W, Kuang Y, Xing X, Simpson RJ, Huang H, Yang T, Chen J, Yang L, Liu E, He W, Gu J. Proteomic comparison of 3D and 2D glioma models reveals increased HLA-E expression in 3D models is associated with resistance to NK cell-mediated cytotoxicity. J Proteome Res 2014; 13:2272-81

90. Jiguet Jiglaire C, Baeza-Kallee N, Denicolai E, Barets D, Metellus P, Padovani L, Chinot O, Figarella-Branger D, Fernandez C. Ex vivo cultures of glioblastoma in three-dimensional hydrogel maintain the original tumor growth behavior and are suitable for preclinical drug and radiation sensitivity screening. Exp Cell Res 2014;321:99-108.

91. Lee KH, Lee KH, Lee J, Choi H, Lee D, Park Y, Lee SH. Integration of microfluidic chip with biomimetic hydrogel for 3D controlling and monitoring of cell alignment and migration. $J$ Biomed Mater Res A 2014;102:1164-72.

92. Levin VA, Panchabhai S, Shen L, Baggerly KA. Protein and phosphoprotein levels in glioma and adenocarcinoma cell lines grown in normoxia and hypoxia in monolayer and three-dimensional cultures. Proteome Sci 2012;10:5.

93. Kievit FM, Florczyk SJ, Leung MC, Veiseh O, Park JO, Disis ML et al. Chitosan-alginate 3D scaffolds as a mimic of the glioma tumor microenvironment. Biomaterials 2010;31:5903-10.

94. An Z, Gluck CB, Choy ML, Kaufman LJ. Suberoylanilide hydroxamic acid limits migration and invasion of glioma cells in two and three dimensional culture. Cancer Lett 2010;292:215-27.

95. Sarkar S, Yong VW. Reduction of protein kinase C delta attenuates tenascin-C stimulated glioma invasion in three-dimensional matrix. Carcinogenesis 2010;31:311-7.

96. Sarkar S, Yong VW. Inflammatory cytokine modulation of matrix metalloproteinase expression and invasiveness of glioma cells in a 3-dimensional collagen matrix. J Neurooncol 2009;91:157-64.

97. Jamison S, Lin Y, Lin W. Pancreatic endoplasmic reticulum kinase activation promotes medulloblastoma cell migration and invasion through induction of vascular endothelial growth factor A. PLoS One 2015; 10:e0120252.

98. Bhatia S, Baig NA, Timofeeva O, Pasquale EB, Hirsch K, MacDonald TJ, Dritschilo A, Lee YC, Henkemeyer M, Rood B, Jung M, Wang XJ, Kool M, Rodriguez O, Albanese C, Karam SD. Knockdown of EphB1 receptor decreases medulloblastoma cell growth and migration and increases cellular radiosensitization. Oncotarget 2015;6:8929-46.

99. Dudu V, Able RA Jr, Rotari V, Kong Q, Vazquez M. Role of Epidermal Growth Factor-Triggered PI3K/Akt Signaling in the Migration of Medulloblastoma-Derived Cells. Cell Mol Bioeng 2012;5:502-413.

100. Yuan L, Zhang H, Liu J, Rubin JB, Cho YJ, Shu HK, Schniederjan M, MacDonald TJ. Growth factor receptor-Src-mediated suppression of GRK6 dysregulates CXCR4 signaling and promotes medulloblastoma migration. Mol Cancer 2013;12:18.

101. Werbowetski-Ogilvie TE, Seyed Sadr M, Jabado N, Angers-Loustau A, Agar NY, Wu J, Bjerkvig R, Antel JP, Faury D, Rao Y, Del Maestro RF. Inhibition of medulloblastoma cell invasion by Slit. Oncogene 2006;25:5103-12.

102. Morrison LC, McClelland R, Aiken C, Bridges M, Liang L, Wang X, Di Curzio D, Del Bigio MR, Taylor MD, Werbowetski-Ogilvie TE. Deconstruction of medulloblastoma cellular heterogeneity reveals differences between the most highly invasive and self-renewing phenotypes. Neoplasia 2013;15:384-98. 